\title{
Distribution of type VI collagen expression in synovial tissue and cultured synoviocytes: relation to fibronectin expression
}

\author{
J Wolf, S E Carsons
}

\begin{abstract}
Type VI collagen has recently been shown to be an important component of connective tissue. Double label immunofluorescence procedures were used to immunolocalise type VI collagen in normal and rheumatoid synovium and its distribution was compared with that of fibronectin. In normal synovium type VI collagen is expressed in the synovial membrane but not in the interstitium of the villus. In rheumatoid synovium, however, type VI collagen is extensively deposited in both the interstitial connective tissue and along the lining of the synovial membrane. Cultured rheumatoid and normal synoviocytes produce type VI collagen and fibronectin and incorporate them into their extracellular matrix. These data suggest that type VI collagen may play a part in matrix remodelling of the inflamed joint.
\end{abstract}

Type VI collagen has been identified as a component of connective tissue derived from placenta, aorta, ligament, skin, cornea, and articular cartilage. ${ }^{1-10}$ Morphologically, it has been localised to fine fibrillar structures associated with $100 \mathrm{~nm}$ periodicity. ${ }^{11}$ Biochemically, type VI collagen is composed of a short triple helix with large globular domains at both ends. ${ }^{12}{ }^{13}$ Type VI $\alpha 1$ and $\alpha 2$ chains have a molecular weight of 140 kilodaltons and can be represented as $\alpha 1(\mathrm{VI}) / \alpha 2(\mathrm{VI})$.

Tissue culture studies show that type VI collagen is synthesised and deposited in the extracellular matrix of fibroblasts and smooth muscle cells. It is not deposited in the extracellular matrix of SV40 transformed fibroblasts, however, and is only weakly detected in the extracellular matrix of human tumour cell lines. ${ }^{6} 111415$ SV40 transformed fibroblasts have been shown to contain low concentrations of mRNA specific for type VI collagen. ${ }^{16} 17$ These data suggest that tissue proliferation may affect type VI collagen expression.

The function of type VI collagen is not clear. In vitro type VI collagen promotes fibroblast cell adhesion. ${ }^{18} 19$ In tendon and placenta it is associated with types I and III collagen bundles, suggesting a structural role. ${ }^{11} 20$

Type VI collagen has also been shown to colocalise with fibronectin in placenta and in neoplasms. ${ }^{2021}$ In tumour the hyperplastic vasculature expressed higher concentrations of type VI collagen than did normal blood vessels.

Rheumatoid arthritis is characterised by a proliferation of the synovial lining associated with an increase in fibronectin deposition..$^{22}$
Previously we showed that type VI collagen is a major extractable component of synovial extracellular matrix. ${ }^{24}$ In this paper we examined the distribution of type VI collagen and compared it with that of fibronectin in tissue sections of normal and rheumatoid synovium and in cultured human synoviocytes.

\section{Methods}

SYNOVIAL TISSUE SPECIMENS

Rheumatoid synovial tissue (eight specimens) was obtained during knee replacement surgery from four patients fulfilling the revised American Rheumatism Association criteria for rheumatoid arthritis. ${ }^{25}$ Normal synovium (two specimens) was obtained from a young patient undergoing diagnostic arthroscopy for trauma. This patient was without clinical or radiographic evidence of arthritis.

Tissue samples were embedded in OCT compound, quick frozen in liquid nitrogen, and stored at $-70^{\circ} \mathrm{C}$ until needed. Sections $(6 \mu \mathrm{m})$ were cut with a cryostat, mounted on slides, and fixed with cold acetone.

\section{SYNOVIOCYTE CULTURES}

Cultures were established and maintained, as previously described, in Dulbecco's modified Eagle's medium (DMEM; Gibco) containing $5 \%$ pooled human serum and antibiotics. ${ }^{26}$ For immunofluorescence studies, first passage cells were dissociated with trypsin-EDTA solution (Gibco) and plated onto $12 \mathrm{~mm}$ round glass coverslips (Bellco), which were placed in 24 well plates (Corning). Cells were plated at $2 \times 10^{4}$ cells/well in DMEM containing $5 \%$ human serum depleted of fibronectin by passage over gelatin-Sepharose. ${ }^{27}$ Cells were grown for seven days before staining and fixation.

\section{IMMUNOFLUORESCENCE PROCEDURES}

All staining in double label immunofluorescence studies was done at $4^{\circ} \mathrm{C}$. Cells were first stained with rhodamine conjugated goat antihuman fibronectin (Jackson ImmunoResearch Laboratories 109-025-059 diluted 1:1) for 45 minutes. Cells were then rinsed three times with phosphate buffered saline (PBS) and incubated for 45 minutes with rabbit antihuman type VI collagen (Telios A112, diluted 1:20). This antibody has been shown to be monospecific for type VI collagen. ${ }^{14}$ Cells were rinsed again three times with PBS and incubated for $\mathbf{4 5}$ minutes with fluorescein conjugated goat antirabbit IgG Fab (Accurate Chemical and Scientific JGZ-1645 
diluted 1:20). The cells were washed three times in PBS, fixed in $95 \%$ alcohol, mounted in glycerol-veronal $\mathrm{NaCl}$ buffer $(1: 1) \mathrm{pH} 8 \cdot 6$, and then examined under a Nikon Labophot microscope equipped with epifluorescent optics. Peak fluorescein and rhodamine spectral transmission were at 445 and $545 \mathrm{~nm}$ respectively. When replicate sections stained by both single and double label procedures were compared, red and green staining patterns were distinctive, suggesting minimal channel cross over.

To control for non-specific binding the cells were incubated with rhodamine conjugated non-immune goat IgG (Jackson Immunoresearch Laboratories 005-020-003, diluted, 1:10), washed, and then incubated with fluorescein conjugated normal rabbit IgG (Organon 10110110 diluted 1:10). No staining was seen. The final protein concentration of the non-immune rhodamine conjugate $(1 \cdot 1 \mathrm{mg} / \mathrm{ml})$ and the rhodamine antifibronectin $(0.65 \mathrm{mg} / \mathrm{ml})$ were similar. Absorption of the rhodamine conjugated antifibronectin with fibronectinSepharose 4B eliminated all staining, whereas incubation with ethanolamine blocked Sepharose 4B did not. Incubation of cells with fluorescein conjugated goat antirabbit IgG Fab' alone at a 1:20 dilution produced no staining.

\section{Results}

DISTRIBUTION OF TYPE VI COLLAGEN IN NORMAL AND RHEUMATOID SYNOVIUM

Immunofluorescent staining of a normal synovial section (fig 1A) showed that type VI collagen sparsely stained the villus membrane (large arrow) and vessel walls (small arrow) and was not present in the interstitium of the villus (arrowhead). In rheumatoid synovial sections (fig 2A) type VI collagen was strongly expressed in the lining of the synovial membrane (large arrow) and in the blood vessel walls (small arrows) as well as in the interstitial connective tissue (arrowhead). This staining pattern was consistently seen in all rheumatoid sections examined.

DISTRIBUTION OF TYPE VI COLLAGEN AND FIBRONECTIN IN NORMAL AND RHEUMATOID SYNOVIUM

Double label immunofluorescent staining of normal synovium (fig 1B) showed that fibronectin was localised to the villus membrane (large arrow) and was strongly expressed in the blood vessel walls (small arrow). Type VI collagen was weakly expressed in these regions (compare figs $1 \mathrm{~A}$ and $\mathrm{B}$ ). In rheumatoid synovium fibronectin (fig 2B) was codistributed with type VI collagen (fig $2 \mathrm{~A}$ ) at the synovial membrane (large arrow), in the interstitium (arrowhead), and in the blood vessel walls (small arrow). Fibronectin staining seemed more dense at the synovial membrane, whereas type VI collagen was more prominent in the interstitial connective tissue.

DISTRIBUTION OF TYPE VI COLLAGEN AND FIBRONECTIN IN CULTURED SYNOVIOCYTES

After seven days in culture normal synoviocytes formed parallel arrays (fig 3C). Type VI collagen staining (fig $3 \mathrm{~A}$ ) colocalised with that of fibronectin (fig 3B) on thick fibrils. A fine
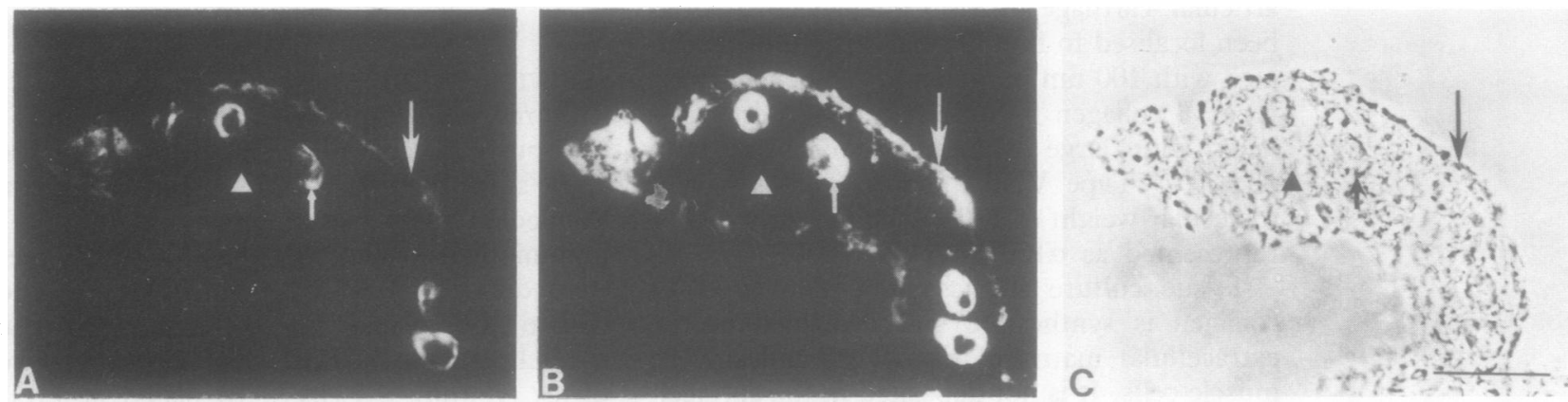

Figure 1 Distribution of type VI collagen and fibronectin in normal synovium. Double immunofluorescence labelling was performed on sections of normal human synovium. Sections were first stained directly with rhodamine conjugated goat antihuman fibronectin and then indirectly with rabbit antihuman type VI collagen followed by fluorescein conjugated goat antirabbit IgG. (A) Indirect staining with anti-type VI collagen; $(B)$ direct staining with antifibronectin; $(C)$ phase contrast photomicrograph of section. Large arrows point to synovial membrane; small arrows point to blood vessels; arrowheads point to interstitium. Bar $=50 \mu \mathrm{m}$.
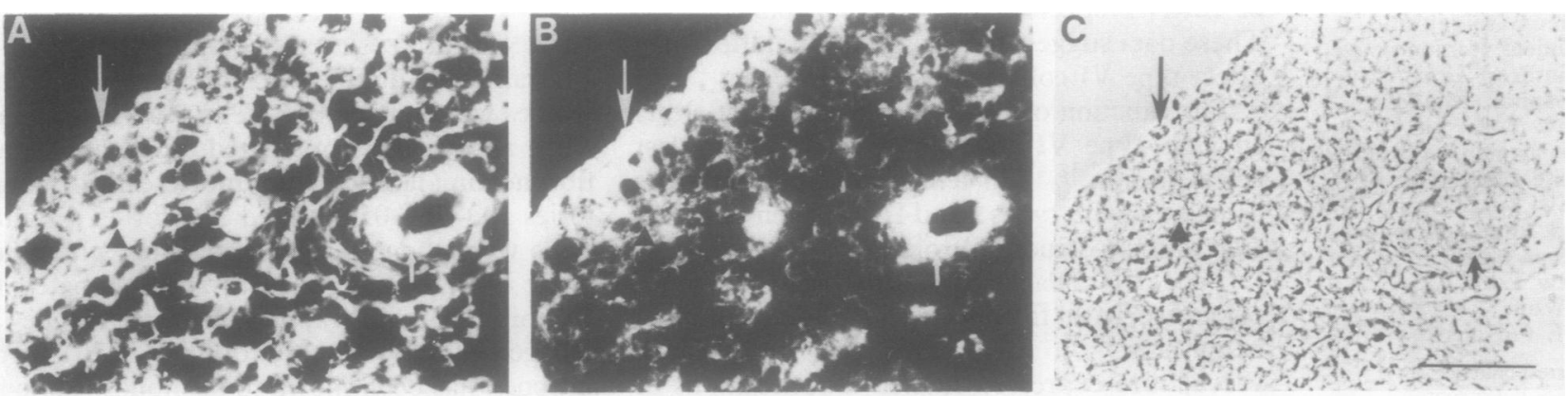

Figure 2 Distribution of type VI collagen and fibronectin in rheumatoid synovium. Double immunofluorescence labelling was performed on sections of rheumatoid synovium. Sections were first stained directly with rhodamine conjugated goat antihuman fibronectin and then indirectly with rabbit antihuman type $V I$ collagen followed by fluorescein conjugated goat antirabbit IgG. (A) Indirect staining with anti-type VI collagen; (B) direct staining with antifibronectin; (C) phase contrast photomicrograph of section. Large arrows point to synovial membrane; small arrows point to blood vessels; arrowheads point to interstitium. Bar $=50 \mu \mathrm{m}$. 

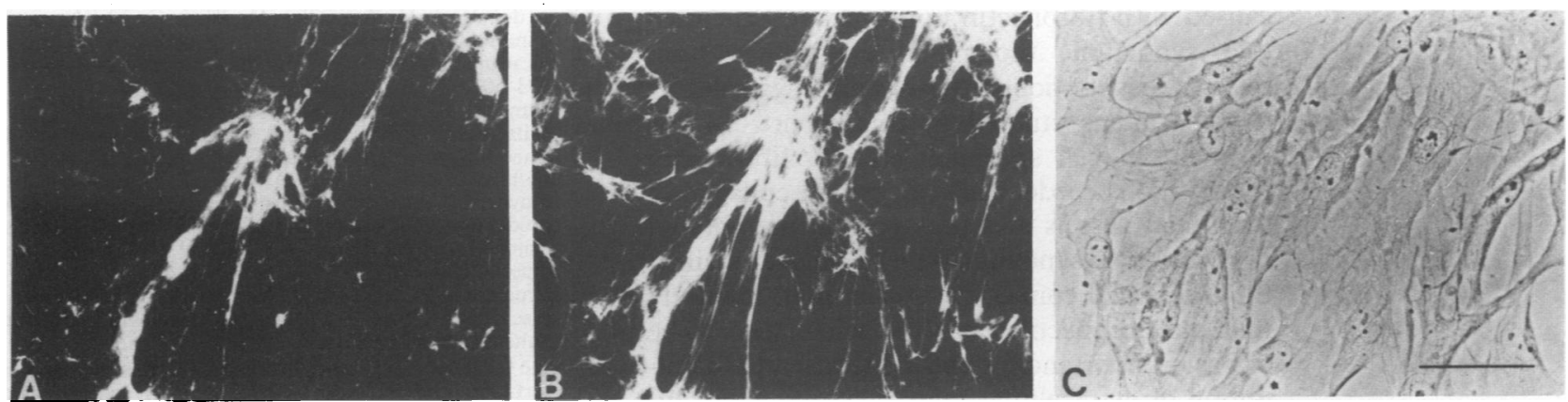

Figure 3 Distribution of type VI collagen and fibronectin in normal synovial cells. Normal synovial cells were grown for seven days before double label immunofluorescence staining was performed. Cells were first stained directly with rhodamine conjugated antifibronectin and then directly stained with rabbit antihuman type VI collagen. (A) Synoviocytes stained with anti-type VI collagen; $;(B)$ synoviocytes stained with antifibronectin; $(C)$ phase contrast photomicrograph. Bar $=50 \mu \mathrm{m}$.
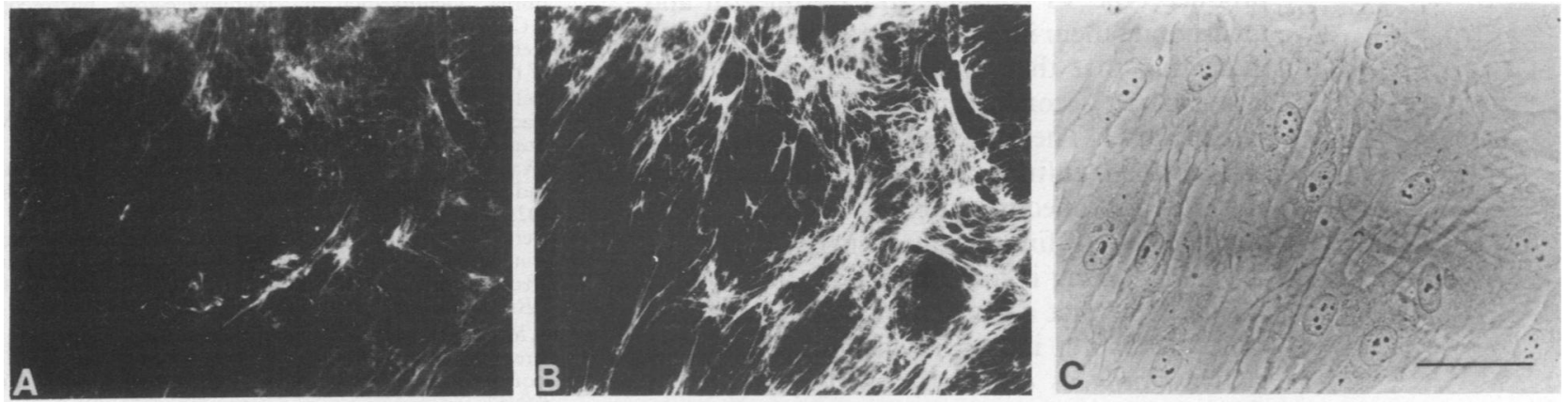

Figure 4 Distribution of type VI collagen and fibronectin in rheumatoid synovium. Rheumatoid synovial cells were grown for seven day's before double label immunofluorescence staining was performed. (A) Rheumatoid synoviocytes stained with anti-type VI collagen; $(B)$ rheumatoid synoviocytes stained with antifibronectin; $(C)$ phase contrast photomicrograph. Bar $=50 \mathrm{im}$.

punctate distribution of type VI collagen was also seen. Rheumatoid synoviocytes cultured for seven days seemed confluent and showed some overlapping and piling up (fig 4C). There was extensive codeposition of fibronectin (fig $4 \mathrm{~B}$ ) and type VI collagen (fig $4 \mathrm{~A}$ ) in the extracellular matrix, forming a network of fine fibrils.

The amount of type VI collagen expressed on matrix fibres of cultured rheumatoid synoviocytes did not exceed that of normal synoviocytes. Expression of type VI collagen in the extracellular matrix of rheumatoid synovium exceeded that of normal synovium.

\section{Discussion}

The distribution of type VI collagen was studied in normal and rheumatoid synovial tissue sections and in cultured rheumatoid and normal synoviocytes. Rheumatoid synovium is characterised by a proliferation of pannus, which is infiltrated by monocyte and fibroblast-like cells. ${ }^{22}$ This is accompanied by an increase in synthesis of extracellular matrix proteins, such as fibronectin, leading to their enhanced deposition.

In the section of normal synovium studied type VI collagen is not expressed in the interstitium of the villus but is expressed in the synovial membrane, suggesting basal synthesis by synoviocytes. Type VI collagen is also found in the blood vessel walls. This is not surprising because type VI collagen has been previously isolated from vascular connective tissue. ${ }^{510}$ In rheumatoid synovium type VI collagen is extensively deposited both in the interstitial connective tissue and along the lining of the synovial membrane, suggesting increased synthesis by the proliferating lining cells and by interstitial connective tissue cells. These findings suggest differences in the expression of type VI collagen between rheumatoid and normal synovium. These differences, however, require validation in further controls matched for age. Previously we have shown that type VI collagen is a major component of pannus and represents about $17 \%$ of extractable protein. ${ }^{24}$ Recently, Levick and McDonald studied normal rabbit synovium by transmission electron microscopy. They suggested that the fibrous long spacing bundles characteristic of synovial microfibrils are composed of type VI collagen. ${ }^{28}$ Trueb et al have shown that type VI collagen is a major extractable component of placenta, uterus, and chicken gizzard. ${ }^{29}$ Recently, Olsen et al reported that type VI procollagen mRNA was the major collagenous gene expressed by skin fibroblasts in culture. ${ }^{30}$ Thus our finding of significant amounts of type VI collagen in synovium is consistent with data showing that type VI collagen is a major component of connective tissue.

Alterations in the amount and distribution of the type VI collagen have been found in other pathological processes. Enhanced type VI collagen deposition has been reported in multiple fibromatosis with multiple articular dysplasia. ${ }^{31}$ Expression of type VI collagen was found to be greatly increased in the hyperplastic vasculature of brain neoplasms compared with the blood vessels of normal brain. ${ }^{21}$ Fibronectin and type VI collagen have been shown to colocalise to matrix fibrils in placenta and in brain neoplasms. ${ }^{2021}$ Similarly, type VI collagen colo- 
calised with fibronectin in normal and rheumatoid synovium, though differences in their relative distribution patterns were suggested by the specimens studied in this report. In the normal synovial specimen studied fibronectin expression exceeded that of type VI collagen in the blood vessels and the synovial membrane. In rheumatoid synovium type VI collagen stained the interstitial connective tissue more intensely than did fibronectin. Both molecules seem to be of basic importance to the structure and stabilisation of extracellular matrix. These data suggest that type VI collagen also has a significant function in the remodelling of synovial connective tissue in chronic arthritis.

Passaged rheumatoid and normal synoviocytes produce type VI collagen and fibronectin and incorporate them into their extracellular matrix, indicating that their presence in pannus is at least in part secondary to their production by synoviocytes. These molecules can be shown to colocalise in culture. In rheumatoid synovial cultures fibronectin staining appears predominantly in fine fibrils, whereas type VI collagen staining is more punctate (fig 4). This may suggest that a fraction of type VI collagen molecules is not incorporated into synoviocyte matrix fibrils as efficiently as fibronectin. In rheumatoid synovium type VI collagen expression appears increased. In vitro, however, where rheumatoid and normal synoviocytes were maintained under the same culture conditions, type VI collagen expression in cultured rheumatoid synoviocytes did not exceed that of normal cells. In vivo, rheumatoid synoviocytes are exposed to high concentrations of cytokines such as transforming growth factor $\beta$, which has been shown to enhance matrix protein expression. ${ }^{32}$

Fibroblast adhesion has been shown to be mediated by type VI collagen $\alpha 2$ and $\alpha 3$ chains. ${ }^{18} 19$ Chu et al reported RGD sequences in the collagenous domain of type VI collagen. ${ }^{16}$ Polypeptides containing these sequences bind to both fibronectin receptors and other extracellular matrix receptors. Wayner and Carter have shown that adhesion receptors for type VI collagen and fibronectin contain a common $\beta$ subunit. ${ }^{33}$ Previously it has been assumed that fibronectin is the major extracellular matrix molecule containing RGD responsible for cell adhesion to synovial matrix. The data reported here suggest that type VI collagen may also be a major determinant of cell adhesion and invasion in synovial tissue.

The authors thank Barbara Diamond for expert technical assistance and Christina Pescatore for preparation of the manuscript. Supported in part by the Arthritis Foundation, New York chapter.

1 Gibson M A, Cleary E G. CL glycoprotein is the tissue form of type VI collagen. $\mathcal{F}$ Biol Chem 1985; 260: 11149-59.

2 Furuto D K, Miller E J. Isolation of a unique collagenous function from limited pepsin digests of human placenta chains. F Biol Chem 1980; 255: 290-5.

3 Jander R, Rauterberg J, Voss B, Von Bassewitz D B. A cysteine-rich collagenous protein from bovine placenta.
Isolation of its constituent polypeptide chains and some properties of the non-denatured proteins. Eur $\mathcal{F}$ Biochem properties of the

4 Odermatt E, Risteli J, Van Delden V, Timpl R. Structural diversity and domain composition of a unique collagenous fragment (intima collagen
5 von der Mark H, Aumailley $M$, Wick G, Fleichmajer $R$, Timpl R. Immunochemistry, genuine size and tissue ocalization of collagen VI. Eur $\mathcal{J}$ Biochem 1984; 142: 493-502.

6 Colombatti A, Bonaldo P. Biosynthesis of chick type VI collagen. II. Processing and secretion in fibroblasts and smooth muscle cells. F Biol Chem 1987; 262: 14461-6.

7 Linsenmayer T F, Mentzer A, Irwin M H, Waldrep N K, Mayne R. Avian type VI collagen. Monoclonal antibody production and immunohistochemical identification as a major connective tissue component of cornea and skeletal muscle. Exp Cell Res 1986; 165: 518-29.

8 Zimmermann D R, Trueb B, Winterhalter $\mathrm{K} \mathrm{H}$, Witmer R, Fischer $R$ W. Type VI collagen is a major component of the human cornea. FEBS Lett 1986; 197: 55-8.

9 Poole C A, Ayard S, Schofield J R. Chondrons from articular cartilage: immunolocalization of type VI collagen in the pericellular capsule of isolated canine tibial chondrons. $\mathcal{f}$ Cell Sci 1988; 90: 635-43.

10 Jander R, Troyer D, Rauterberg J. A collagen-like glycoprotein of the extracellular matrix is the undegraded form of type VI collagen. Biochemistry 1984; 23: 3675-81.

11 Burns R R, Press W, Engvall E, Timpl R, Gross J. Type VI collagen in extracellular $100 \mathrm{~nm}$ periodic filaments and fibrils: identification by immunoelectron microscopy. 7 Cell Biol 1986; 103: 393-404.

12 Trueb B, Bornstein P. Characterization of the precursor form of type VI collagen. $\mathcal{F}$ Biol Chem 1984; 259: 8597-604.

13 Engel J, Furthmayr H, Odermatt E, et al. Structure and Acad Sci 1985; 460: 25-37.

14 Engvall E, Hessle H, Klier G. Molecular assembly, secretion and matrix deposition of type VI collagen. $\mathcal{F}$ Cell Biol 1986; 102: 703-10.

15 Carter W G. Transformation-dependent alterations in glycoproteins of the extracellular matrix of human fibroblasts. Corctization of GP250 and the collagen-like GP140. F Biol Chem 1984; 259: 13805-15.

16 Chu M L, Mann K, Deutzmann R, et al. Characterization of three constituent chains of collagen type VI by peptide sequences and cDNA clones. Eur $\mathcal{F}$ Biochem 1987; 168 : 309-17.

17 Trueb B, Schaeren-Wiemers N, Schreier T, Winterhalter K H. Molecular cloning of chicken type VI collagen. Primary structure of the subunit 2 (VI) pepsin. F Biol Chem 1989; 264: $136-40$.

18 Carter $W \mathrm{G}$. The cooperative role of the transformationsensitive glycoproteins, GP140 and fibronectin in cell attachment and spreading. I Biol Chem 1982; 257: 3249-57.

19 Aumailley M, Mann K, von der Mark H, Timpl R. Cell attachment properties of collagen type VI and arg-gly-aspdependent binding to its $2(\mathrm{VI})$ and 3 (VI) chains. Exp Cell Res 1989; 181: 463-74.

20 Amenta P S, Gay S, Vaheri A, Martinez-Hernandez A. The extracellular matrix is an integrated unit: ultrastructural localization of collagen types I, III, IV, V, VI, fibronectin and laminin in human term placenta. Collagen Relat Res 1986; 6: 125-52.

21 McComb R D, Moul J M, Bigner D D. Distribution of type VI collagen in human gliomas: comparison with fibronectin and glioma-mesenchymal matrix glycoprotein. I Neuropathol Exp Neurol 1987; 46: 623-33.

22 Hendersen $B$. Biochemistry of the human synovial lining with special reference to alterations in metabolism in rheumatoid arthritis. Pathol Res Pract 1981; 172: 1-24.

23 Scott D L, Delamere J P, Walton $K$ W. The distribution of fibronectin in the pannus in rheumatoid arthritis. $B r \mathcal{F} E x p$ Pathol 1981; 62: 362-7.

24 Wolf J, Carsons S, Lavietes B B, Diamond H S. Synovial extracellular matrix: partial characterization of matrix components and identification of type VI collagen molecular forms. Clin Exp Rheumatol 1991; 9: 51-4.

25 Ropes M W, Bennett G A, Cobb S, Jacox R, Jessar R A. 1958 Revision of diagnostic criteria for rheumatoid arthritis. Bull Rheum Dis 1958; 9: 175-6.

26 Lavietes B B, Carson S E, Diamond H S, Laskin R S. Synthesis, secretion and deposition of fibronectin in cultured human synovium. Arthritis Rheum 1985; 78: 1016-26.

27 Carsons S E, Mosesson MW, Diamond H S. Detection and quantitation of fibronectin in patients with rheumatic disease. Arthritis Rheum 1981; 24: 1261-8.

28 Levick J R, McDonald J N. Microfibrillar meshwork of the synovial lining and associated broad banded collagen: a clue synovial lining and associated broad banded col

29 Trueb B, Schreier T, Bruckner P, Winterhalter K H. Type VI B, Jcheier T, Bruckner $\mathrm{P}$, frestion tissue collagens. Eur $\mathcal{J}$ Biochem 1987; 166: 699-703.

30 Olsen B R, Peltonen J, Jaakkola S, Chu M L, Uitto J. Collagen gene expression by cultured human skin fibroblasts. Abundant steady state levels of type VI procollagen messenger. RNAs. $\mathcal{J}$ Clin Invest 1989; 83: 791-5.

31 Murata K, Motoyama T, Suka M, Ohno M, Kuboki Y. High production of type VI collagen in multiple fibromatosis with multiple articular dysplasia. Biochem Biophys Res Comeman 1987; 147: 275-81.

32 Ignotz $\mathbf{R}$ A, Massague J. Transforming growth factor- $\beta$ stimulates the expression of fibronectin and collagen and their incorporation into extracellular matrix. $\mathcal{F}$ Biol Chem 1986; 261: 4337-45.

33 Wayner E, Carter $\mathbb{W}$ G. Identification of multiple cell adhesion receptors for collagen and fibronectin in human fibrosarcoma cells possessing a unique and common B subunits. F Cell Biol 1987; 105: 1837-84. 